\title{
Medico-Legal Issues in Air Gun Injuries
}

\author{
Gunethilake Kmtb ${ }^{1}$, Prof. Muditha Vidanapathirana, \\ ${ }^{I}$ Consultant Judicial Medical Officer, Provincial General Hospital, Ratnapura, Sri Lanka, \\ ${ }^{2}$ Professor of Forensic Medicine, Department of Forensic Medicine, Faculty of Medical Sciences, \\ University of Sri Jayewardenepura
}

\begin{abstract}
Introduction: The only difference of airgun with rest of firearms is it propels projectile by means of compressed air. Air gun injuries are uncommon in Sri Lanka as it is not commonly used. However, it seems to be promoting since recently. There are no laws related to air guns and anybody can buy for the purpose of hunting and a license is not needed.

Case report: An 8 year old boy was admitted with an injury to the right hand. According to father, the injury was due to an accidental fall. There was a circular shape $3 \mathrm{~mm}$ perforated laceration with $5 \mathrm{~mm}$ abraded margin at the base of right palm. However, there were no evidence of burning, blackening or tattooing. X-ray examination revealed a dumbbell shaped radio-opaque foreign body in the right wrist damaging the epiphysis of the radius. A metallic foreign body was surgically removed. Later, it was revealed that the child received injuries while playing with one of his relative children with an air gun.

Conclusions: The findings were compatible with injuries caused by an air gun. Although air guns can be used in meaningful manner, it is dangerous in children's hands. Though no reported fatal cases in Sri Lanka, they can be modified and use for dangerous purposes. Therefore, it is recommended to develop regulations and control on air guns.
\end{abstract}

Keywords: Air guns, injuries, regulations

\section{Introduction}

Airgun is believed to be a form of firearm, as it is a barrel weapon and shot discharges a pallet. Only difference with rest of firearms is it propels a projectile by means of compressed air [1]. Air gun injuries are uncommon in Sri Lanka as it is not commonly used. But it is relatively common in countries like United States. According to US consumer products, two millions of air guns are sold annually in USA [2].In Sri Lanka, even thoughusages of air guns are uncommon, since recently it seems to be promoting. There are no laws related to airguns and anybody can buy for the purpose of hunting and a license is not required. Further, newspaper articles are published to sell air guns. It is an accepted sport in schools of Sri Lanka.

\section{Case report}

An 8 year old boy was admitted with an injury to the right hand. According to father,the injury was due to an accidental fall. There was a circular shaped $3 \mathrm{~mm}$ perforated laceration with $5 \mathrm{~mm}$ abraded margin at the base of right palm (Figure 1).However, there were no evidence of burning, blackening or tattooing. X-ray examination of the right hand and wrist revealed a dumbbell shapedradio-opaque foreign body in the wrist (Figure 2) damaging the epiphysis of the radius. A dumbbell metallic foreign body with pointed tip and hollow back was removedsurgically from the distal end of the wound tract (Figure 3).Later, it was revealed that the child received injuries while playing with one of his relative childrenwith an air gun.

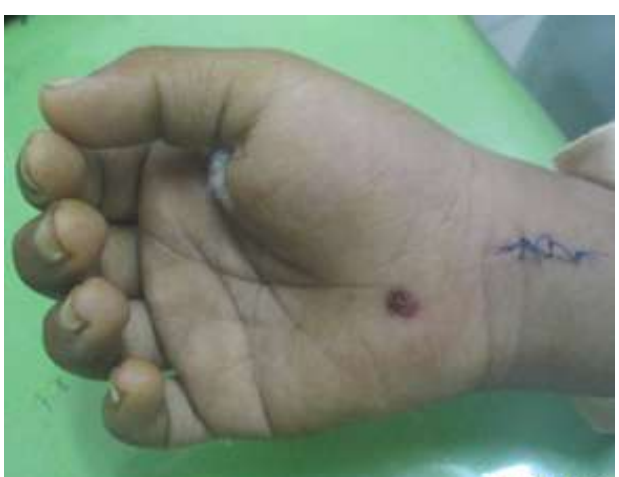

Figure 1. Three $\mathrm{mm}$ perforated laceration with $5 \mathrm{~mm}$ abraded margin

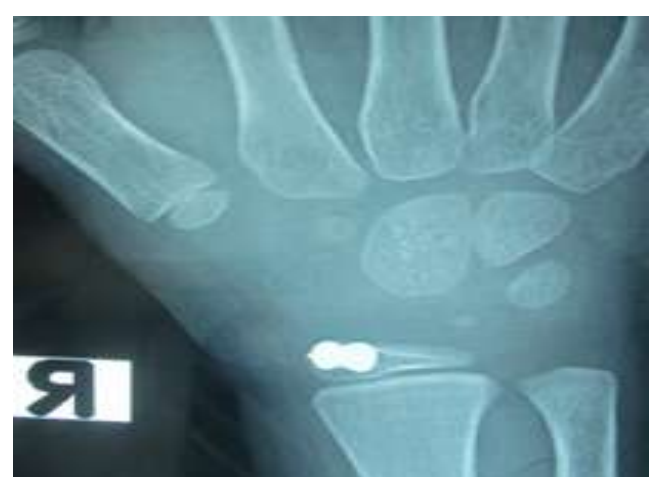

Figure 2. Dumbbell shaped radio-opaque foreign body in the right wrist 


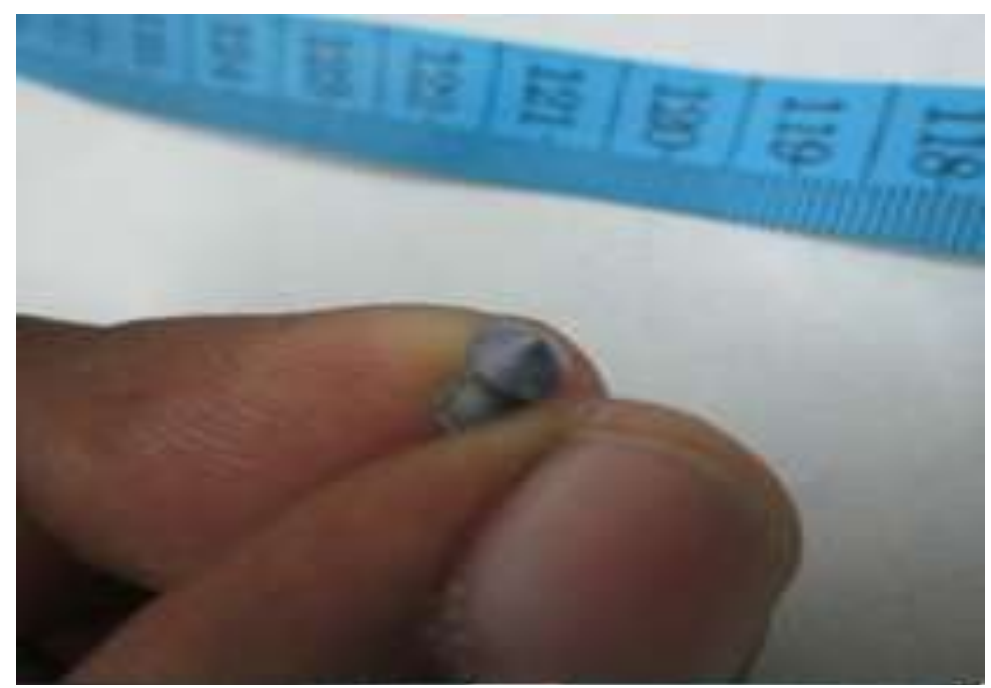

Figure 3. The pellet recovered from the wrist.

\section{Discussion}

The pellet found in this case was dumbbell in shape with pointed head, constricted waist and hollow back. The shape of air gun pellets usually called diabolo or wasp waist shaped, where the mid part is constricted as in a body of a wasp and from the waist back, the pellet is hollow. The solid head is usually sized to fit the bore just touching the rifling and it keeps the pellet centred in the bore. The head can be flat, round, hollow or pointed tip. This is the most common pellet design find today [3]. Therefore, the pelletrecovered from the injury was examined and was confirmed as that of an air gun pellet.

The entry wound had a perforated laceration and an abraded margin but did not have features due to secondary projectiles of explosives such as burning, blackening or tattooing [4]. Therefore, the injury was more suggestive of due to a gun powered by pressurised air rather than gun powered by explosives. Further, the father, stated that the injury was caused by an air gun while the victim was playing with another relative child. Therefore, the injuries were compatible the given history of pellet discharged from an air gun.

However, the firearms and their injuries are dealt under "Firearm ordinance of Sri Lanka" [5]. According to the ordinance, gun means "any barrelled weapon of any description from which any shot, pellet or other missile can be discharged with sufficient force to penetrate not less than eight straw boards". In addition, air guns propel projectiles by means of compressed air, whereas in ordinary firearms, it is by burning of explosives. Therefore, airguns operate at pressures as low as 50 atmospheres, while firearms operate at thousands of atmospheres [6]. Further, the firearm ordinance directly excludes air gun as a firearm. According to the ordinance "any weapon of whatever description, designed or adapted for the discharge of any noxious substance is also considered as a firearm, except air gun" ("gun"(d) subs by s 2(3) of Act 22 of 1996) [5]. Therefore, according to Sri Lankan law, air gun is not considered as a firearm.

This has created a medico-legal issue regarding the categorization of the injuries in the "Medico-legal examination form (MLEF)", because a forensic medical practitioner has to mention the "type of injuries" and "type of weapon" in it. Since "injuries" caused by air guns cannot be categorized under firearm injuries, we mentioned them under ordinary injuries; abrasions and lacerations. Further, when indicating the "type of weapon", though we usually mention as firearm, in this case, it was mentioned as air gun. Since the pellet damaged the epiphyseal cartilage of the hand, it was categorized as grievous hurt.

When the head is flat, as found in match pellets, it retards the penetration and ensures the safety [3]. When the head of the pellet is pointed, it could cause serious injuries to soft tissues. Among them, eye injuries are a serious problem [6]. In this case, the head of the pellet was pointed and it facilitated the penetration of the wrist of the child.

Further,injuriesdue to modern air guns can be serious or even fatal because most modern air guns can exceed the velocity of conventional hand guns [7]. Pellet guns, can be dangerous weapons that are often marketed to children. A study done in 2015 revealed, in recent decades, advances in compressed-gas technology has led to a significant increase in the power and muzzle velocity and the risk of intracranial injury in children due to non-powder pellet weapons has increased. They have the ability to penetrate a child's skull and brain [8]. Therefore, awareness should be raised among parents, children, and policy makers as to the risk posed by air guns.

According to a study done in USA from 2002-2012 showed that air guns are rising in popularity and account for the majority of pediatric eye injuries requiring hospital admissions. These may lead to permanent 
eye injury. Therefore, they insisted to increase the regulations for sales, and usage of air guns to prevent serious pediatric eye injuries [9].

Most of the time, the air guns are used to hunt small animals. Sometimes, air guns are used by children as a toy. According to a study, the average age of the victims those who got injured was 10.9 years [2]. Similarly, in this case, the age of the child was 8 years. Therefore, the air gun injuries are especially dangerous to children.Further, victimsare most commonly shot by a friend or sibling [2]. Similarly, in the current case, the child received injuries while playing with one of his relatives.

According to the same above study, $71 \%$ of the injuries were unintentional, $5 \%$ were assaults, and $1 \%$ were suicides [2]. In this case, the pellet injury was found in the palm. When a pellet injury is found in palm, it is usually considered as a defence injury. However, the possibility of homicidal injury was excluded based on the history of the child and the guardian. Therefore, it was ascertained that the injuries were received due to unintentional fire.

\section{Conclusions}

Although air guns can be used in meaningful manner, it is dangerous in children's hands. Though no reported fatal cases in Sri Lanka, they can be modified and use for dangerous purposes. Therefore, it is recommended to develop regulations and control air guns.

\section{References}

[1]. Air gun. Wikipedia. https://en.wikipedia.org/wiki/Air_gun. [Retrieved on 06.02.2016]

[2]. Laraque D, Injury Risk of Non-powder Guns. Paediatrics. Nov2004; 114 (5): 1357-61.

[3]. Pellets - air gun. https://en.wikipedia.org/wiki/Pellet_\%28air_gun\%29. [Retrieved on 6.02.2016]

[4]. Knight B. Gunshot injuries in Forensic Pathology, $2^{\text {nd }}$ Ed, Arnold, London, 1996. P. 267

[5]. Firearms Ordinance (1916) Arrangement of Sections, Blackhall Publishing 3: 33.

[6]. Jim H. "Huntng with airguns. Chapter 6". crosman.com.Crosman. http://www.crosman. Com/get - hunting/airgun-ballistics. [Retrieved on 6.02.2016]

[7]. Bowen DI, Magauran DM. Ocular injuries caused by airgun pellets: an analysis of 105 cases.British Medical Journal. 1973 Feb; 10;1(5849):333-7.

[8]. Ceylan H, McGovan M, Stringer MD.Air weapon injuries:Aserious and persistant problem. Archives of Diseases of Children. 2002;86:234-235.

[9]. Kumar R, Kumar R, Mallory GW, Jacob JT, Daniels DJ, Wetjen NM, et al. Penetrating head injuries in children due to BB and pellet guns: a poorly recognized public health risk.Journal of Neurosurgery, Pediatrics. 2015 Oct; 23:1-7.

[10]. Lee R, Fredrick D. Pediatric eye injuries due to non-powder guns in the United States, 2002-2012. Journal of American association of paediatric ophthalmology strabismus. 2015 Apr;19(2):163-8.e1. doi: 10.1016/j.jaapos. 2015.01.010. 